\title{
Uphill Transport of Urea in the Dog Kidney: Effects of Certain Inhibitors*
}

\author{
Martin Goldberg, $†$ Andrzej M. Wojtczak, $\$$ and Manuel A. Ramirez $\S$ \\ (From the Renal-Electrolyte Section, Department of Medicine, University of Pennsylvania \\ School of Medicine, Philadelphia, Pa.)
}

\begin{abstract}
Summary. To study the renal medullary transport and accumulation of urea in dogs independent of water transport, we obliterated the medullary electrolyte gradient by a sustained ethacrynic acid diuresis. Infusions of urea were also given at various rates to vary urinary urea concentration. In the steady state, the kidneys were removed, and slices were analyzed for water, urea, and electrolytes. In every experiment in 15 dogs over a range of urinary urea concentration from 19 to 230 mmoles per $\mathrm{L}$ and urine flow from 0.5 to $9.7 \mathrm{ml}$ per minute per kidney, an intrarenal urea gradient persisted, and urinary urea concentration was always lower than papillary water urea concentration. The magnitude of this uphill urinary-papillary gradient (mean $\pm \mathrm{SE}=-21 \pm 2.9$ mmoles per $\mathrm{L}$ ) was not affected by hemorrhagic hypotension or a nonprotein diet.

In 12 additional experiments begun similarly, inhibitors were infused into one renal artery. Both iodoacetate, an inhibitor of anaerobic glycolysis, and acetamide, an analogue of urea, markedly and significantly reduced both the intrarenal urea gradient and the uphill urinary-papillary gradient. In contrast, cyanide, an inhibitor of oxidative metabolism, had no observable effect on the urea gradients. The data are best explained by postulating an active transport system for urea in the medullary collecting duct deriving its energy from anaerobic glycolysis.
\end{abstract}

\section{Introduction}

It has long been recognized that urea plays a unique role in the renal concentrating mechanism

* Submitted for publication August 11, 1966; accepted November 14, 1966.

Supported by U. S. Public Health Service grants HE 00340-C16-C17 and HE 07284-04-05.

A preliminary report of this work was presented at the 50th Annual Meeting of the Federation of American Societies for Experimental Biology in Atlantic City, N. J., April 12, 1966. Published in Fed. Proc. 1966, 25, 203.

† Work supported by a Research Career Development Award from the National Institute of Arthritis and Metabolic Diseases, U. S. Public Health Service grant 5K3AM18582-04,-05. Address requests for reprints to Dr. Martin Goldberg, 860 Gates Pavilion, 3400 Spruce Street, Philadelphia, Pa. 19104.

¥Visiting investigator, University of Pennsylvania School of Medicine. Present address: Second Dept. of Medicine, Poznan, Poland.
(1-3), and that the renal medulla of the hydropenic animal (4-5) has a marked capacity to concentrate urea with an increasing gradient towards the papillary tip. Microcatheterization studies in the golden hamster have indicated that urea enters the medullary interstitium from the medullary collecting ducts (6). Berliner, Levinsky, Davidson, and Eden hypothesized that urea is transported passively in the renal medulla (3). Accordingly, all medullary urea transport is thought to be secondary to prior water movement from the collecting duct, which raises the intratubular urea concentration; this creates the downhill concentration gradient favoring the diffusion of urea through the epithelial wall of the collecting duct. Vasopressin, which increases the permeability of the toad bladder (7) and collecting tubular epithelia

§ Present address: British-American Hospital, Lima, Peru. 
(8) to water, is also presumed to increase the permeability of the collecting duct to passive urea transfer (9). Therefore, all urea transport is indirectly dependent on the maintenance of an intramedullary electrolyte gradient, which is responsible for the osmotic flow of water out of the lumen of the collecting duct, and thus creates the favorable urea gradient.

There are some species, such as the elasmobranch fishes (10), in which active tubular reabsorption of urea seems to exist. In the rat, protein depletion and mannitol diuresis can produce higher concentrations of urea in renal papillary water than in the final urine $(5,11,12)$. These data have been interpreted as suggesting active transport of urea across the collecting duct. This concept recently has been supported by the micropuncture studies of Lassiter, Mylle, and Gottschalk (13), which revealed a higher urea ${ }^{14} \mathrm{C}$ concentration in the vasa recta than in the collecting duct at the same level. However, the applicability of data on urea transport in the rat to other species, such as dog and man, has been questioned (5).

We designed the present study to test the hypothesis of passive urea transport in the dog's renal medulla by studying medullary urea accumulation in the steady state when the medullary electrolyte gradient was obliterated with ethacrynic acid. Our data revealed that under these conditions a medullary urea gradient was still maintained, and furthermore, an uphill concentration gradient for urea between final urine and papillary tip was present. The effects on this uphill urea gradient of iodoacetate, an inhibitor of anaerobic glycolysis; cyanide, an inhibitor of oxidative metabolism; and acetamide, a possible competitive inhibitor, were also investigated.

\section{Methods}

A total of 30 acute experiments were performed in 30 female mongrel dogs weighing 20 to $25 \mathrm{~kg}$. For 1 week before the experiment, 27 animals were maintained on a standard diet containing more than $100 \mathrm{~g}$ protein per day and adequate minerals and vitamins. In three a synthetic nonprotein diet similar to that utilized by Manitius, Pigeon, and Epstein (14) was substituted for the standard diet. On the day before each experiment, water was withheld, and $5 \mathrm{U}$ of Pitressin tannate in oil was administered. After the induction of light anesthesia with intravenous sodium pentobarbital, a midline abdominal incision was made, the ureters were isolated near their entrance to the urinary bladder, and polyethylene cannulas were inserted up to the pelvis of each kidney. A priming dose of creatinine was administered intravenously, followed by a sustaining infusion of isotonic saline at a rate of $1 \mathrm{ml}$ per minute containing adequate amounts of creatinine for clearance determinations plus aqueous Pitressin given at a rate of $50 \mathrm{mU}$ per $\mathrm{kg}$ per hour throughout the experiment. Cannulas were inserted into the femoral artery for blood sampling and into the femoral vein for subsequent administration of the various loading solutions. The following experimental modifications were then utilized.

Mannitol-urea diuresis. Three preliminary experiments were performed $\left(\operatorname{dogs} U_{1}, U_{2}, U_{3}\right)$ in which diuresis was induced by the intravenous infusion of $10 \%$ mannitol at a rate of 12 to $15 \mathrm{ml}$ per minute. When total urine flow (V) from both kidneys reached 16 to $18 \mathrm{ml}$ per minute, the mannitol was stopped and a solution of $8 \%$ urea in $75 \mathrm{mM}$ saline was infused at a comparable rate until a stable diuresis was maintained for 45 to 60 minutes at $\mathrm{V}$ of 20 to $24 \mathrm{ml}$ per minute. For the last few collection periods, the urine was collected separately from each kidney. The renal pedicles were then clamped, and both kidneys were rapidly removed and immediately frozen in a mixture of acetone and dry ice. They were subsequently sliced and analyzed for urea, electrolytes, and water as described below.

Ethacrynic acid diuresis alone. Thirty to 45 minutes after instituting the priming and sustaining clearance infusions, we gave an intravenous priming dose of ethacrynic acid of $1.25 \mathrm{mg}$ per $\mathrm{kg}\left(\operatorname{dogs} \mathrm{D}_{1}, \mathrm{D}_{2}, \mathrm{D}_{4}, \mathrm{D}_{15}\right)$. This was followed immediately by a sustaining infusion of ethacrynic acid in 5\% dextrose and water administered at a rate of $1.25 \mathrm{mg}$ per $\mathrm{kg}$ per hour for the remainder of the experiment. One to 2 hours after the priming dose of ethacrynic acid, when $\mathrm{V}$ was stable and urinary osmolality was virtually isotonic for three to four 5-minute collection periods, both kidneys were removed and frozen.

Standard protocol: ethacrynic acid-urea diuresis. The experiments were begun with an ethacrynic acid diuresis as outlined above (dogs $\left.U_{4}-U_{7}, U_{15}, U_{20}\right)$. In addition, to serve as a control procedure for subsequent studies involving intra-arterial infusions, both renal arteries were dissected free, and in dogs $U_{15}$ and $U_{20}$ isotonic saline at a rate of $0.25 \mathrm{ml}$ per minute was infused into each kidney throughout the experiment. Once a stable state of diuresis due to ethacrynic acid was achieved for several periods, an intravenous infusion of $8 \%$ urea in $75 \mathrm{mM}$ saline was added. This was given at various rates in the different experiments so as to achieve different steady state values of $\mathrm{V}$ and urinary urea concentrations ( $U_{\text {urea }}$ ) at the end of the experiment. When $\mathrm{V}$ was stable within 1 to $2 \mathrm{ml}$ per minute for 30 to 45 minutes during the combined ethacrynic acid-urea diuresis, the urine was collected separately from each kidney for two to four collection periods, after which both kidneys were removed and frozen. In several experiments, in order to prevent marked sodium depletion and a sharp fall in glomerular filtration rate (GFR), we gave additional isotonic saline after institution of ethacrynic acid diuresis. 
Standard protocol plus hemorrhage. In two additional experiments (dogs $U_{8}, U_{8}$ ), in order to study the effects of hemorrhagic hypotension and to reduce $\mathrm{V}$ markedly while still maintaining a reasonably high filtered load of urea, we removed arterial blood from the femoral artery during the ethacrynic acid-urea diuresis to lower mean arterial blood pressure (BP) to approximately $50 \mathrm{~mm}$ $\mathrm{Hg}$ (from previous values exceeding $100 \mathrm{~mm} \mathrm{Hg}$ ). BP was monitored with a mercury manometer. During stable $\mathrm{V}$ and $\mathrm{BP}$, the kidneys were removed and frozen.

Standard protocol plus nonprotein diet. Dogs $\mathrm{U}_{10}$, $U_{11}$, and $U_{12}$ received a synthetic nonprotein diet for 1 week before we performed standard ethacrynic acid-urea diuretic experiments.

Experiments involving use of inhibitors. In 12 experiments, the study was begun with an ethacrynic acid diuresis. In all of these animals, during the initial preparations, both renal arteries (before the bifurcation) were dissected free and no. 23-gauge needles inserted into each vessel, the tip pointing against the direction of blood flow. The needles were kept open with infusions of isotonic saline at a rate of $0.25 \mathrm{ml}$ per minute. A saline infusion to the contralateral renal artery was maintained, and this served as the control kidney. The dosages of both cyanide and iodoacetate chosen were in the dose range already demonstrated by Fujimoto, Nash, and Kessler (15), and by Herms and Malvin (16), to have had definite unilateral effects on renal function (urinary osmolality, sodium excretion, or both) compared to the contralateral control.

Cyanide. In three such experiments (dogs $\mathrm{U}_{31}, \mathrm{U}_{32}$, $\mathrm{U}_{3 s}$ ), sodium cyanide was infused into one kidney at a rate of $0.012 \mathrm{mg}$ per $\mathrm{kg}$ per minute (approximately $2.4 \times$ $10^{-3}$ mmole per $\mathrm{kg}$ per minute). Thirty minutes after initiating the cyanide infusion, the intravenous infusion of $8 \%$ urea was begun, and 60 to 70 minutes later, during a stable. V, both kidneys were removed and frozen. The mean total dose of cyanide per kidney per experiment was approximately 0.4 mmole.

Iodoacetate. In three experiments (dogs $\mathrm{U}_{21}, \mathrm{U}_{23}, \mathrm{U}_{24}$ ) monoiodoacetate was infused into one renal artery during stable ethacrynic acid diuresis at a rate of 0.10 to $0.15 \mathrm{mg}$ per kg per minute (approximately 5.3 to $7.4 \times 10^{-3}$ mmole per $\mathrm{kg}$ per minute). Forty to 60 minutes later, the intravenous infusion of $8 \%$ urea was started, and the experiment was terminated with removal of the kidneys approximately 50 to 60 minutes later during stable V. The mean total dose of iodoacetate per animal was 1.2 mmoles. Three additional experiments with iodoacetate were performed (dogs $U_{14}, U_{17}, U_{18}$ ), in which comparable doses of iodoacetate were infused into one renal artery for 80 to 100 minutes after the institution of the combined ethacrynic acid-urea diuresis. Thus, in three animals, iodoacetate was given before the urea infusion, and in three others iodoacetate was given after the urea diuresis was established.

Acetamide. In dogs $\mathrm{U}_{28}, \mathrm{U}_{27}$, and $\mathrm{U}_{28}$, during the ethacrynic acid diuresis, a solution containing acetamide in quantities calculated to provide a renal arterial blood level of approximately 45 mmoles per $L$ was infused into one renal artery in place of the saline infusion. This infusion was continued for 30 minutes, after which it was replaced by a solution infused at the same rate which contained the same concentration of acetamide plus urea at a concentration equal to one-half that of acetamide. A solution containing the identical concentration of urea was also simultaneously infused into the renal artery of the control kidney. Thus, acetamide and urea were infused in 2:1 proportions into the experimental kidney, and only urea was infused into the control. In approximately 60 minutes, during stable $\mathrm{V}$ from both kidneys, the kidneys were removed and frozen.

Processing of renal tissue and chemical analyses. The kidneys of all experimental animals plus ten kidneys from five nondiuretic hydropenic animals were frozen and sliced in the manner described below.

Two cross-sectional slices approximately $\frac{1}{4}$ inch thick were taken from near the center of each frozen kidney. With a cartilage knife, slices perpendicular to the corticopapillary axis were taken from cortex, outer papilla (i.e., peripheral portion of the inner zone adjacent to the outer zone of the medulla), and the tip of the papilla. Each slice was divided longitudinally into two pieces, each weighing 100 to $300 \mathrm{mg}$. We dried one in an oven at 103 to $105^{\circ} \mathrm{C}$ for 48 hours to estimate water content of tissue. The dried tissue, after weighing, was then digested with $5 \mathrm{ml}$ of concentrated nitric acid, after which the solution was diluted with water; sodium and potassium were determined by flame photometry.

The second piece of each slice, after weighing, was transferred to a mortar and pestle for homogenization and dilution with $10 \mathrm{ml}$ distilled water. One-ml samples of this homogenate were taken in duplicate for determination of urea by the Conway microdiffusion technique (17). Ammonia blanks were done in each analysis. Preliminary experiments revealed that the precision of the determination of urea concentration in tissue water in our laboratory was 1 to 2 mmoles per $\mathrm{L}$ or better in duplicate specimens, and recovery from tissue was 100 $\pm 0.5 \%$. In each experiment, sodium, potassium, urea, ammonia, and water content were determined on two slices from each kidney at a given level (cortex, outer papilla, and papillary tip); the values were averaged to yield the mean value of that level in a given kidney.

Dialysis of tissue homogenates. To assess the extent of tissue protein binding of urea, we performed two additional in vitro experiments. Each was begun by inducing an ethacrynic acid diuresis in a dog. During stable V, the kidneys were removed and the inner white medulla from each kidney was removed and homogenized in a mortar and pestle, with sufficient isotonic saline to provide no more than $1: 2$ to $1: 3$ dilution of the tissue. Isotonic saline solution was used as the dialyzing fluid. In experiment 1 , sufficient urea was added to homogenate and dialyzate to provide approximately equivalent concentrations of urea on both sides of the membrane before dialysis. In experiment 2 , no urea was added to the predialysis dialyzing fluid. Dialyses were performed for 240 minutes with a cuprophane membrane suspended between two Lucite chambers, each with a capacity of 2.5 
ml. Turbulance was maintained on each side of the membrane by bubbling air through the dialyzate and homogenate.

All blood and urine specimens were analyzed for osmolality; sodium, potassium, creatinine, and urea by methods described previously (18). Urea was determined by the Conway microdiffusion technique (17). Osmolar clearance $\left(\mathrm{C}_{\mathrm{osm}}\right)$ and solute-free water reabsorption $\left(\mathrm{T}_{\mathrm{H}_{2} \mathrm{O}}^{\mathrm{C}}\right)$ were calculated as follows: $\mathrm{C}_{\mathrm{osm}}=$ $\left(\mathrm{U}_{\mathrm{osm} m} \times \mathrm{V}\right) / \mathrm{P}_{\mathrm{osm}}$, and $\mathrm{T}_{\mathrm{H}_{2} \mathrm{O}}^{\mathrm{c}}=\mathrm{C}_{\mathrm{osm}}-\mathrm{V} ; \mathrm{U}_{\mathrm{osm}}=$ urinary osmolality (milliosmoles per kilogram), $\mathrm{P}_{\text {osm }}=$ plasma osmolality (milliosmoles per kilogram), and $\mathrm{V}=$ urine flow (milliliters per minute). Statistical calculations were done with standard techniques (19).

\section{Results}

Mannitol-urea experiments. Because mannitol diuresis has been a technique used in rats to produce a higher urea concentration in the renal papilla than in final urine $(5,12)$, three preliminary experiments with mannitol diuresis followed by urea diuresis were performed. In these experiments, during stable $\mathrm{V}$ from both kidneys greater than $17 \mathrm{ml}$ per minute, the urine was still hypertonic (mean $\mathrm{U}_{\mathrm{osm}} / \mathrm{P}_{\mathrm{osm}}=1.21$ ), and there were still intrarenal gradients for both urea and nonurea solute from cortex to papillary tip. In two of the three dogs $\left(U_{1}\right.$ and $\left.U_{2}\right)$, the urea concentration of papillary tip water was lower than final urinary urea concentration. Mean $\Delta$ [urea] (i.e., $\mathrm{U}_{\text {urea }}$ minus papillary water urea concentration) of all kidneys in these animals was +16 mmoles per L. In $\operatorname{dog} \mathrm{U}_{3}, \Delta$ [urea] of the left and right kidneys was -5 and -7 mmoles per $L$, respectively. An uphill urea gradient was, therefore, present in one of three dogs (two of six kidneys), but the difficulty of reproducing this phenomenon in the dog made it necessary to utilize a different approach to study urea transport.

Experiments utilizing ethacrynic acid. When an experiment was initiated by a sustained ethacrynic acid diuresis, an uphill urinary-papillary gradient (negative $\Delta$ [urea]) was produced in every instance, except in those kidneys subjected to certain inhibitors (vide infra). Table I outlines a typical ethacrynic acid-urea experiment (standard protocol) in $\operatorname{dog} U_{4}$. During the initial ethacrynic acid diuresis $U_{\text {urea }}$ fell to very low levels, but it was subsequently elevated by the urea infusion to a higher steady state level at the end of the experiment. The renal tissue and urinary analytical data of this experiment $\left(\operatorname{dog} \mathrm{U}_{4}\right)$ are con-
TABLE I

$A$ representative experiment utilizing standard protocol in dog $U_{4}^{*}$

\begin{tabular}{lccccc}
\hline \hline Time & Uosm & Posm & $\mathrm{V}$ & $\mathrm{U}_{\text {urea }}$ & GFR \\
\hline $\min$ & $\mathrm{mOsm} / \mathrm{kg}$ & $\mathrm{mOsm} / \mathrm{kg}$ & $\mathrm{ml} / \mathrm{min}$ & $\mathrm{mmoles} / \mathrm{L}$ & $\mathrm{ml} / \mathrm{min}$ \\
$0-21$ & 1942 & 308 & 0.36 & 1,152 &
\end{tabular}

21-100 Cannulate both ureters; combine urine from both kidneys; start priming and sustaining creatinine and Pitressin. Infuse $0.85 \%$ saline at $4 \mathrm{ml} / \mathrm{min}$. Priming dose of ethacrynic acid, $1.25 \mathrm{mg} / \mathrm{kg}$; start sustaining ethacrynic acid, $1.25 \mathrm{mg} / \mathrm{kg} / \mathrm{hr}$.

$\begin{array}{llllll}170-175 & 311 & 312 & 12.8 & & 71 \\ 175-180 & 310 & 311 & 12.0 & & 68 \\ 180-185 & 310 & 314 & 11.1 & 17 & 77\end{array}$

185 Start $8 \%$ urea at $16 \mathrm{ml} / \mathrm{min}$.

Start collecting urine separately from each kidney.

245-250

$\begin{array}{llllll}\mathrm{L} & 400 & 410 & 9.6 & 166 & 24\end{array}$

$\begin{array}{rrrrrrr}250-256 & & & & & \\ & \mathrm{~L} & 406 & 418 & 8.7 & 176 & 21\end{array}$

256 Both kidneys removed and frozen.

* Standard protocol = hydropenia-ethacrynic acid-8\% urea.

Abbreviations: $\mathrm{U}_{\mathrm{osm}}=$ urinary osmolality; $\mathrm{P}_{\mathrm{osm}}=$ plasma osmolality; $\mathrm{V}=$ urine flow; $\mathrm{U}_{\text {urea }}=$ urinary urea concentration; and $\mathrm{GFR}=$ glomerular filtration rate.

tained in Table II, which summarizes the tissue and urinary data from all experiments employing ethacrynic acid without the use of inhibitors. Both kidneys from $\operatorname{dog} \mathrm{U}_{4}$ show total obliteration of the intrarenal electrolyte gradient. In striking contrast, an intrarenal urea gradient was still present; furthermore, the papillary tip urea concentration of both kidneys was higher than the ipsilateral pelvic urinary urea concentration. For the left and right kidneys $\Delta$ [urea] was -29 and -37 mmoles per L, respectively.

From Table II, it can be seen that a downhill or positive $\Delta$ [urea] was present only in the hydropenic controls, where an intramedullary electrolyte gradient was also present. In every other experiment, regardless of the $U_{u r e a}, V, G F R$, or plasma urea concentration, an uphill or negative $\Delta$ [urea] was obtained. Neither hemorrhage nor protein depletion had a strong influence on the magnitude of the uphill urea gradient, since there was no significant difference statistically in the $\Delta$ [urea] among groups $\mathrm{C}, \mathrm{D}$, and $\mathrm{E}$ of Table II. The grand mean $\Delta$ [urea] \pm standard error for all 
M. GOLDBERG, A. M. WOJTCZAK, AND M. A. RAMIREZ

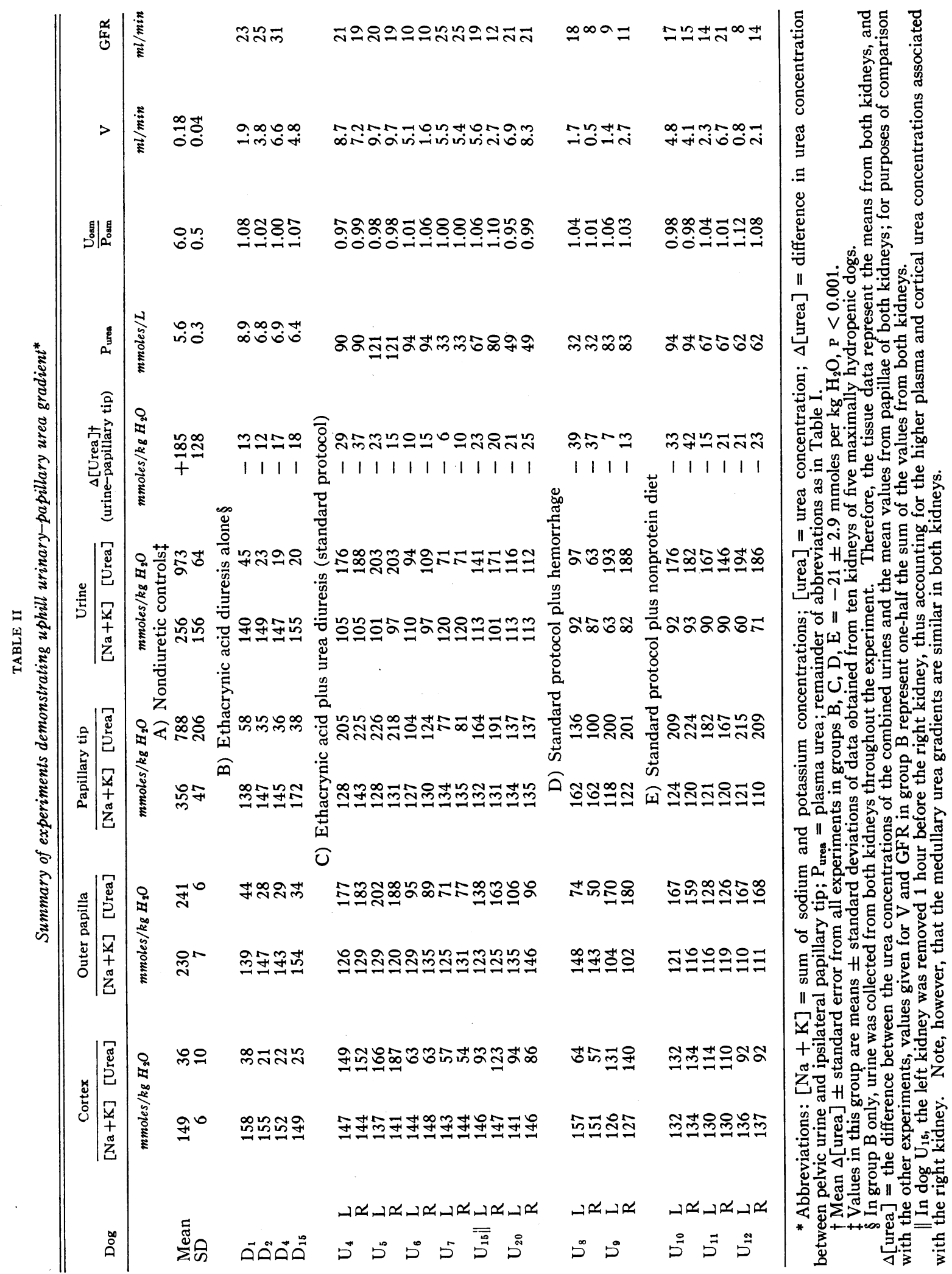


the experimental kidneys was $-21 \pm 2.9$ mmoles per L, $\mathrm{p}<0.001$.

The effects of $U_{u r e a}$ and of $V$ on the magnitude of $\Delta$ [urea] are illustrated in Figures 1 and 2, respectively. In these charts, in addition to the data from the experiments listed in Table II, the data from the control kidneys of the 12 experiments that utilized inhibitors are also plotted. In Figure $1, U_{\text {urea }}$ is plotted against urea concentration of papillary water. Since every point lies below the $45^{\circ}$ line, it is apparent that an uphill urinary-papillary gradient was present in every experiment. Furthermore, it is clear that the magnitude of this gradient was not specifically related to $U_{\text {urea, }}$ which varied from 19 to 230 mmoles per L. This gradient did not appear to be altered significantly by hemorrhagic hypotension (upright triangles) or a nonprotein diet (inverted triangles). Similarly, as illustrated in Figure $2, \Delta$ [urea] was not closely related to urine flow, which varied from 0.5 to $11.6 \mathrm{ml}$ per minute per kidney.

Effects of sodium cyanide. Figure 3 summarizes the renal tissue and urinary concentrations of urea in the three animals prepared ac-

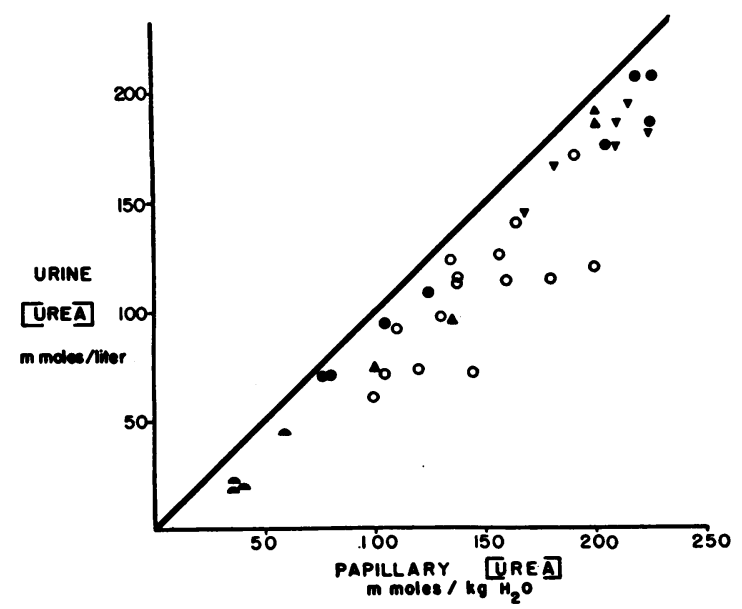

Fig. 1. Relationship BETWEen URINARY AND PAPILLARY UREA CONCENTRATIONS. Symbols: half circle $=$ ethacrynic acid diuresis alone; solid circle $=$ standard protocol (ethacrynic acid + urea diuresis); upright triangle $=$ standard protocol + hemorrhage ; inverted triangle $=$ standard protocol + nonprotein diet; open circle $=$ control kidneys of experiments using metabolic inhibitors (see text). Note that every point lies below the $45^{\circ}$ line, indicating an uphill urinary-papillary gradient over a broad range of urinary and papillary urea concentrations.

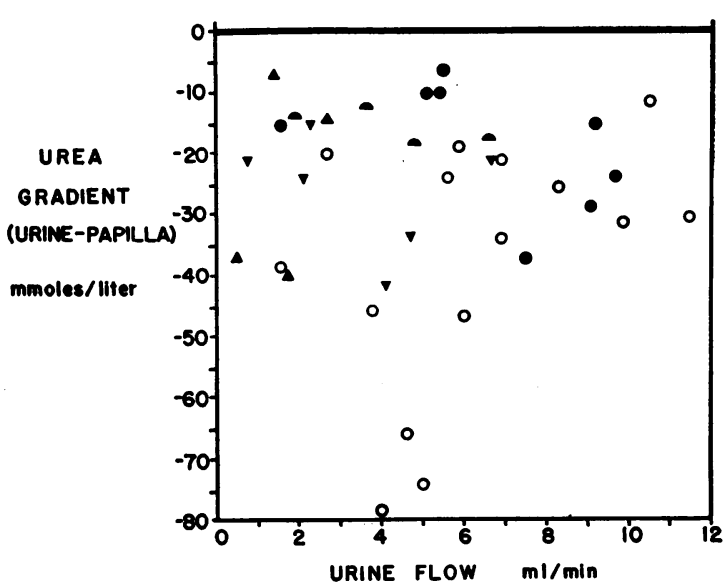

Fig. 2. Relationship Between Magnitude of UREA GRADIENT (URINARY UREA CONCENTRATION MINUS UREA CONCENTRATION OF PAPILLARY TIP WATER) AND URINE FLOW PER KIDNEY. The gradient was not affected by varying urine flow over a wide range. Symbols are the same as in Figure 1.

cording to the standard protocol which also received sodium cyanide in one rena! artery $\left(U_{31}\right.$, $\left.\mathrm{U}_{32}, \mathrm{U}_{33}\right)$. The data from dog $\mathrm{U}_{20}$ are also presented for comparison. This was an experiment in which both renal arteries were dissected free, and only isotonic saline was infused into them throughout the experiment. It is apparent that in

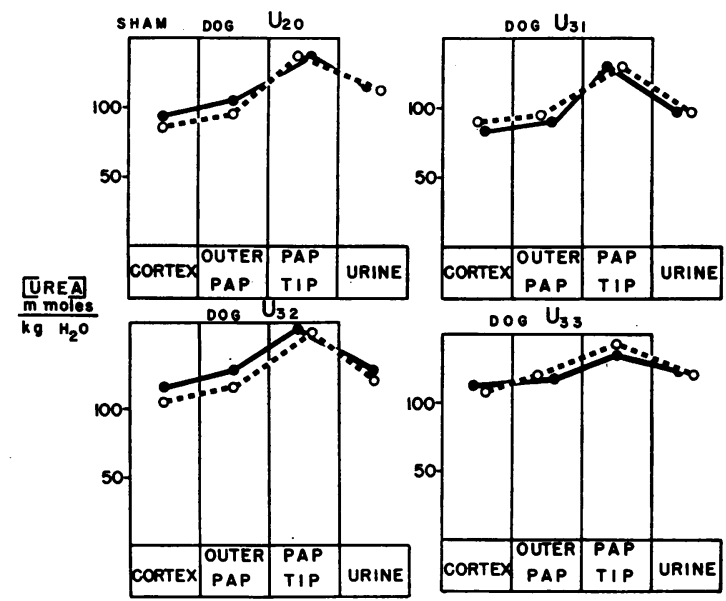

Fig. 3. EFFects OF SODIUM CYANIDE ON INTRARENAL AND URINARY-PAPILLARY UREA GRADIENTS. In each eXperiment the solid line and circles represent the control kidney, and the broken line and open circles represent the experimental kidney, which received cyanide (dogs $U_{31}, U_{32}$, and $\left.U_{38}\right)$. Dog $U_{20}$, a sham experiment, was prepared exactly as the other animals, but isotonic saline was infused into both kidneys. $\mathrm{PAP}=$ renal papilla. Note the absence of any effects of cyanide. See text. 
every cyanide experiment the intrarenal urea concentration pattern and the uphill urinary-papillary urea gradient were virtually the same in the control kidneys (solid lines) and the experimental kidneys (broken lines). Hence, doses of cyanide as great as those already used by Fujimoto and his colleagues (15) to demonstrate definite effects on renal oxygen consumption and sodium reabsorption had no demonstrable effect on the renal distribution of urea or on the uphill urinary-papillary urea gradient. The mean difference between the experimental $\Delta$ [urea] and the control $\Delta$ [urea] was $-4.7, \mathrm{p}>0.25$. In the 11 experiments in which the conditions were similar for both kidneys and no inhibitors were used, there was also no significant difference between the two kidneys of a given animal in the magnitude of the uphill urinary-papillary gradient (standard error of mean difference $=3.2, \mathrm{p}>0.5$ ).

Effects of iodoacetate. Two types of experiments utilizing monoiodoacetate were performed. In one group (dogs $U_{16}, U_{17}, U_{19}$ ), iodoacetate was infused into one renal artery after the institution of both the ethacrynic acid and the urea diureses. Thus, some buildup of papillary urea concentration was allowed to occur before the use of iodoacetate. The results from these experiments are presented in Table III. In dogs $U_{16}$ and $U_{17}$, unlike all other experiments with inhibitors, the control kidneys were removed and frozen before the infusion of iodoacetate into the experimental kidneys. This accounts for the higher plasma and cortical urea concentrations in the experimental kidneys in these studies. In $\operatorname{dog} \mathrm{U}_{19}$, the control kidney remained in situ until the end of the entire experiment. Regardless of the different base lines, however, these data show that the intrarenal urea gradient of the experimental kidney was sharply reduced and the $\Delta$ [urea] of the experimental kidney was less than that of the control kidney by twothirds to three-fourths, a difference that is statistically significant $(p<0.02)$. There were no consistent differences in $\mathrm{V}$ and GFR between the control and experimental kidneys that might be invoked to account for these differences.

In a second group of three experiments (dogs $\left.\mathrm{U}_{21}, \mathrm{U}_{23}, \mathrm{U}_{24}\right)$, which are summarized in Figure 4, iodoacetate was begun before initiation of the urea infusion. Both kidneys were removed together at the end of the experiment. Under these con-

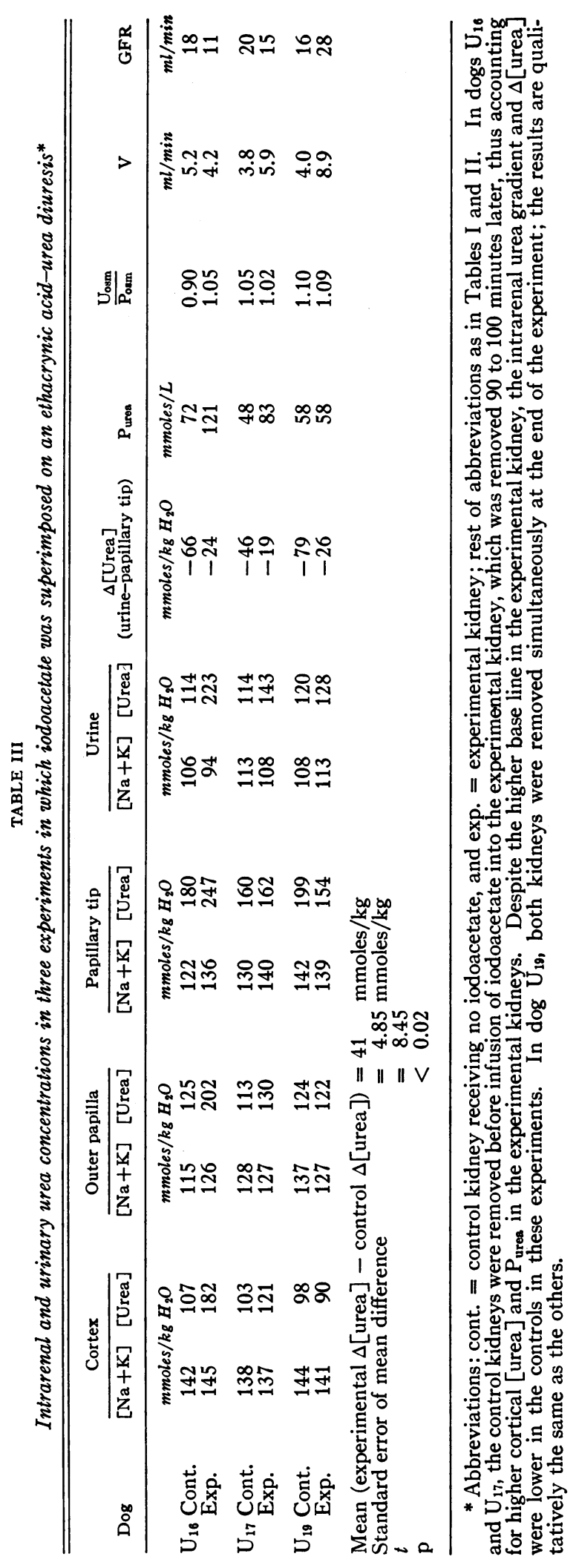




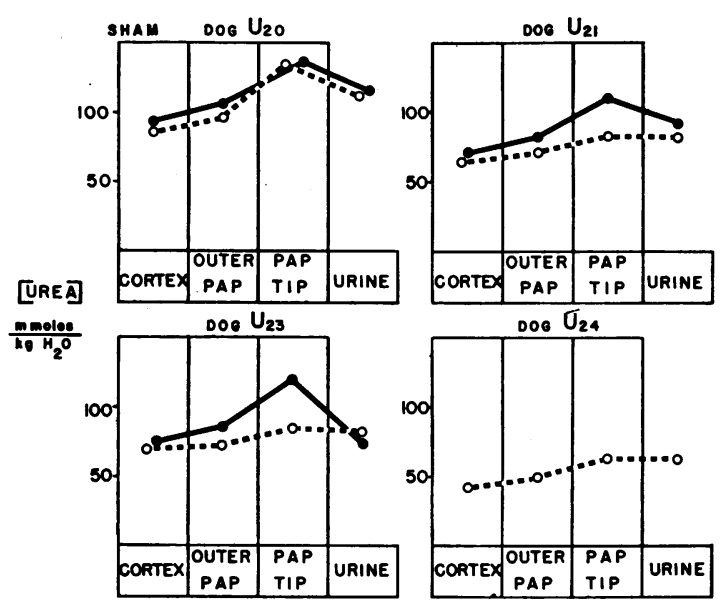

Fig. 4. EFFECTS OF IODOACETATE ON INTRARENAL AND URINARY-PAPILLARY UREA GRADIENTS. Dog $U_{20}$ is a sham experiment, shown for comparison. Note the marked lowering of the intrarenal gradient and the obliteration of the uphill urinary-papillary gradient in all experimental kidneys (broken line) compared to contralateral control kidneys (solid line). In dog $\mathrm{U}_{24}$, the control kidney was inadvertently lost. See text.

ditions, compared to the control kidneys, the intrarenal urea gradient of the experimental kidneys was almost totally abolished, and the uphill $\Delta$ [urea] was virtually obliterated. In the experimental kidneys of dogs $U_{21}, U_{23}$, and $U_{24} \Delta$ [urea] was $-1,-3$, and 0 mmoles per $\mathrm{L}$, respectively, whereas $\Delta$ [urea] of the control kidneys of $U_{21}$ and $\mathrm{U}_{23}$ was -18 and -47 mmoles per $\mathrm{L}$, respectively. Data on the control kidney of $U_{24}$ are absent because the renal artery was inadvertently torn during dissection, and the organ could not be used. However, the results from the experimental kidney conform so closely to the others in this series and are so uniquely different from all other control observations that they are included. Data from $\operatorname{dog} U_{20}$, a control animal, are also shown in Figure 4 for comparison. The differences in $\Delta$ [urea] between experimental and control kidneys in all iodoacetate experiments of both types are highly significant $(\mathrm{p}<.005)$.

Effects of acetamide. Data from three experiments (dogs $U_{26}, U_{27}, U_{28}$ ) in which acetamide and urea were infused into the experimental kidney and urea alone was simultaneously administered to the control kidney are illustrated in Figure 5. It is apparent that, in the presence of acetamide, there was a sharp reduction in the medullary urea gradient; furthermore, the uphill $\Delta$ [urea] was

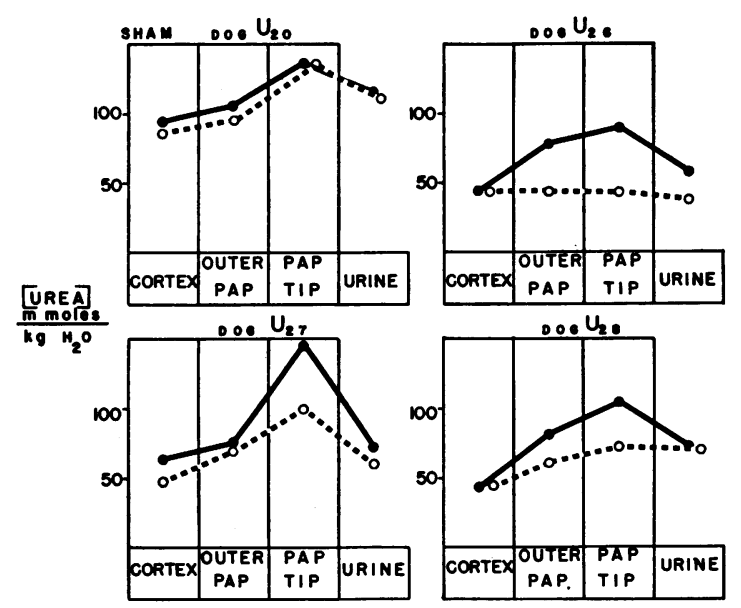

Fig. 5. EFFects OF ACETAMIDE ON INTRARENAL AND URINARY-PAPILLARY UREA GRADIENTS. As in Figures 3 and 4 , dog $U_{20}$, a sham experiment, is illustrated for comparison. In dogs $U_{28}, U_{27}$, and $U_{28}$, the intrarenal urea gradients are markedly reduced in the experimental kidneys receiving acetamide (broken line) compared to the contralateral control (solid line). See text.

virtually abolished in dogs $U_{28}$ and $U_{28}$ and sharply reduced in $\operatorname{dog} U_{27}$. The $\Delta[$ urea] of the experimental kidney, which received acetamide, was significantly different from that of the control $(p<0.001)$.

Thus, to summarize the results of the experiments with inhibitors, both iodoacetate and acetamide reduced the intrarenal urea gradient and the uphill urinary-papillary gradient for urea. On the other hand, no effects on these variables were observed with sodium cyanide. No innate differences between two kidneys in the same animal were observed in experiments similarly performed without the use of specific inhibitors.

In vitro dialysis experiments. These data are summarized in Table IV. They indicate no differential distribution of urea at equilibrium between the homogenate and dialyzate. If tissue protein binding of urea were a significant factor influencing our results, then a higher concentration of

TABLE IV

Dialysis of homogenates of renal papilla

\begin{tabular}{cccccc}
\hline \hline \multirow{2}{*}{$\begin{array}{c}\text { Experiment } \\
\text { no. }\end{array}$} & \multicolumn{2}{c}{ Predialysis [urea] } & & \multicolumn{2}{c}{ Postdialysis [urea] } \\
\cline { 2 - 3 } \cline { 5 - 6 } & Homogenate & Dialyzate & & Homogenate Dialyzate \\
\hline & \multicolumn{2}{c}{ mmoles $/ L$} & & \multicolumn{2}{c}{ mmoles $/ L$} \\
2 & 78.9 & 79.2 & & 78.9 & 79.2 \\
2 & 64.4 & 0 & & 35.7 & 35.5 \\
& & 0 &
\end{tabular}


urea on the tissue side would be expected; such was not the case.

\section{Discussion}

Although active tubular reabsorption of urea has been inferred from studies in the elasmobranch (1), rat (5, 11-13), and sheep (20), this report represents the first study in which an uphill urinary-papillary urea gradient has been reproducibly demonstrated in the dog. This is of particular importance because, heretofore, the strongest arguments for passive urea transfer in the renal medulla have been based largely on clearance $(9,21)$, stop flow $(22)$, and tissue slice studies $(23,24)$ performed in the dog. The critical procedure in our experiments was the administration of ethacrynic acid, a drug which inhibits sodium transport in the loop of Henle $(18,25)$, thereby obliterating the intramedullary electrolyte gradient as observed on tissue analysis. Hence, the osmotic gradient for water removal from the collecting duct was eliminated $\left(\mathrm{U}_{\mathrm{osm}} / \mathrm{P}_{\text {osm }}\right.$ approached $1.0, \mathrm{~T}^{\mathrm{c}} \mathrm{H}_{2} \mathrm{O}$ approached zero). Despite the fact that net water reabsorption in the final concentrating operation was virtually nonexistent, medullary urea transport and the accumulation of urea along a rising intramedullary concentration gradient were still present.

Micropuncture (26) and microcatheterization (6) studies on urea transport in the rodent have revealed that the major direct source of medullary urea was the collecting duct (11). Although the details of the direction of urea movement in the dog kidney have not been so well worked out, studies by Clapp (12) indirectly suggest the presence of a medullary system of urea circulation in the dog kidney qualitatively similar to that in the rat, in which a major fraction of filtered urea is reabsorbed in the collecting duct. If this is true, our data indicate the presence of a steady state uphill transport gradient for urea.

Although this uphill transport gradient in itself suggests active transport of urea, other possible explanations involving passive transfers of urea must be evaluated. Solvent drag appears to be an unlikely mechanism because it cannot produce a solute concentration on the distal side of the membrane higher than in the solution of origin. Evidence for urea production by kidneys of the chicken in vivo (27) and the frog in vitro (28) has been presented. If this occurred in the renal medulla, then de novo urea synthesis could contribute to the total medullary urea concentration and theoretically, at least, might raise tissue urea concentration to values above that in final urine. There is no evidence, however, that renal synthesis of urea plays a quantitatively significant role physiologcally. In the chicken, Owen and Robinson (27) could find no evidence that urea synthesis was the source of a significant fraction of excreted urea unless arginine was infused. In the rat, Truniger and Schmidt-Nielsen (11) observed that the specific activity of medullary urea ${ }^{14} \mathrm{C}$ was no different from that in plasma and renal cortex; and Lassiter and associates (13) found that urea ${ }^{14} \mathrm{C}$ concentration of blood in the vasa recta was greater than that in the collecting duct. These observations suggest, therefore, that the contribution of a urea-producing system in the renal medulla to the total urea concentration of tissue water or vasa recta plasma is negligible.

The binding of a large proportion of papillary urea to tissue protein could also account for an apparently higher urea concentration in tissue water than in urine in our experiments. This is because urea and water contents were determined independently, and the aqueous concentration of urea was then calculated. Under these conditions, the "true" aqueous tissue urea concentration could be lower than that of collecting duct urine, thus favoring passive downhill diffusion, whereas apparent "total" tissue urea concentration, which included bound urea, would be higher than that of final urine. No evidence has been provided, however, which indicates that mammalian tissue proteins bind urea to any measurable degree. Furthermore, dialysis experiments performed by Lassiter and co-workers on plasma proteins of the rat (13) and by us on canine medullary tissue have failed to uncover evidence for binding of sufficient magnitude to account for our results. In addition, the fact that iodoacetate reduced or obliterated the uphill urinary-papillary gradient argues strongly against simple physical or physicochemical binding. Still possible, but perhaps unlikely, would be a urea-binding system requiring energy derived from anaerobic glycolysis.

When the experiments with the various inhibitors are taken into consideration, the most likely 
explanation for all of our observations is that urea is actively transported from the collecting duct into the medullary interstitium. Because iodoacetate, an inhibitor of anaerobic glycolysis (29), distinctly affected the uphill urea gradient and cyanide, an inhibitor of the electron transport system, had no measurable effect, it appears that, under our experimental conditions, the energy supply for medullary urea transport was derived principally from anaerobic metabolism. This conclusion is also compatible with our observation that both the intrarenal urea gradient and the uphill urinary-papillary gradient were maintained, despite the presence of hemorrhagic hypotension and renal ischemia. Schirmer (30) studied the in vitro metabolism of canine renal medullary slices after prolonged clamping of the renal artery and found a remarkable capacity of the medulla to maintain glycolysis despite severe ischemia. Kean, Adams, Winters, and Davies (31) hypothesized that most, if not all, of the chemical energy utilized in the renal medulla was derived from anaerobic metabolism. They based their conclusion on in vitro studies that revealed a high rate of glycolysis in the renal medulla and also on the principles of countercurrent exchange, which predict a low oxygen tension in the inner medulla. They speculated further that this system was the major energy source for sodium transport in the countercurrent multiplier system. Although this may be true, attention should also be directed to the possibility that medullary anaerobic glycolysis is of equal or greater importance in the transport of urea.

The effects of acetamide, a compound structurally related to urea, in reducing the intrarenal accumulation of urea and markedly lowering the uphill urinary-papillary gradient also support the concept of active urea transport. There are several examples wherein acetamide and another urea analog, methylurea, are transported similarly. In the renal medulla of the rat, where uphill urea transport appears to occur, both acetamide and methylurea accumulate in a manner qualitatively similar to urea (11); in the renal tubules of the elasmobranch, these compounds are actively reabsorbed in a manner similar to urea, but thiourea is not (32). Rabinowitz and Kellogg (33) have shown in the dog that both acetamide and methylurea and a few other analogues were capable of enhancing the concentrating ability of the kidney in a manner resembling the action of urea. Hence, in our own experimental system, acetamide may share the same transport or carrier sites as urea and thus serve as a competitive inhibitor of urea transport. An alternative, but less likely, explanation for the observed effects of acetamide in our studies is that this compound competes with urea for certain specific tissue protein-binding sites.

Several questions concerning the nature of the proposed urea transport system and its relationship to water reabsorption and to the effects of vasopressin remain to be answered. Our observation that the magnitude of the urinary-papillary uphill gradient was reasonably stable over a wide range of $\mathrm{V}$ and $\mathrm{U}_{\text {urea }}$ may be pertinent. This finding could be explained if the urea transport system in the collecting duct, rather than being limited by the tubular load of urea presented to it, is, in fact, a gradient-limited system, and under the conditions of our experiments the limiting concentration gradient was unmasked. This interpretation is also compatible with the concept that the higher the tubular concentration of urea relative to the interstitial concentration, the more favorable are the conditions for urea transport. Thus, under normal hydropenic conditions, which favor a very high collecting tubular urea concentration due to the high rate of water reabsorption in the distal tubule and collecting duct, this energy dependent system is transporting urea downhill along its chemical gradient. Any condition that lowers the urea concentration of fluid entering the collecting duct, such as water diuresis or solute diuresis, would provide a transtubular gradient less favorable for optimal urea transport and reduce the rate of urea reabsorption. Likewise, any condition directly reducing the net reabsorption of water from the collecting duct, such as the absence of vasopressin or, more completely, the obliteration of the medullary electrolyte gradient, would also inhibit urea reabsorption and, in the latter case, unmask the limiting uphill transport gradient. Whether urea reaches the medullary interstitium by active transport, as suggested by our data, or by passive mechanisms, it would accumulate in the inner medulla according to the principles of countercurrent exchange involving the vasa recta (3) and increase papillary and urinary osmolality. An active transport system 
could, in addition, account for the increase in urinary nonurea solute concentration observed under certain conditions after administration of urea and protein $(11,14)$.

The above hypothesis on urea transport in the collecting duct requires no direct effect of vasopressin on urea permeability. Rather, vasopressin, which alters water permeability of the distal nephron, might indirectly influence urea transport by changing intratubular urea concentration. Although vasopressin increases the permeability of the toad bladder to both water and urea ( 7$)$ and in vitro perfusion studies of rat collecting duct have been interpreted as suggesting similar effects (34), recent direct observations indicate that vasopressin acts on the distal tubule of the rat (35) and the collecting tubule of the rabbit (8) to change their permeability to water and not to urea. These latter findings are perfectly compatible with our hypothesis outlined above.

\section{Acknowledgments}

We wish to thank Mrs. Lydia Kosolapovs and Mr. Leonids Kosolapovs for the meticulously performed laboratory analyses, Mr. Kenneth Christy for his technical assistance, and Dr. J. Russell Elkinton for his support and encouragement throughout the study. We also thank the Merck Sharpe and Dohme Research Laboratories for the generous supply of ethacrynic acid.

\section{References}

1. Gamble, J. L., C. F. McKhann, A. M. Butler, and E. Tuthill. An economy of water in renal function referable to urea. Amer. J. Physiol. 1934, 109, 139.

2. Crawford, J. D., A. P. Doyle, and J. H. Probst. Service of urea in renal water conservation. Amer. J. Physiol. 1959, 196, 545.

3. Berliner, R. W., N. G. Levinsky, D. G. Davidson, and M. Eden. Dilution and concentration of the urine and the action of antidiuretic hormone. Amer. J. Med. 1958, 24, 730.

4. Ullrich, K. J., and K. H. Jarausch. Untersuchungen zum Problem der Harnkonzentrierung und Harnverdünnung. UUber die Verteilung von Elektrolyten ( $\mathrm{Na}, \mathrm{K}, \mathrm{Ca}, \mathrm{Mg}, \mathrm{Cl}$, anorganischem Phosphat), Harnstoff, Aminosäuren und exogenem Kreatinin in Rinde und Mark der Hundeniere bei verschiedenen Diuresezuständen. Pflügers Arch. ges. Physiol. 1956, 262, 537.

5. Bray, G. A., and A. S. Preston. Effect of urea on urine concentration in the rat. J. clin. Invest. 1961, 40, 1952.
6. Klümper, J. D., K. J. Ullrich, and H. H. Hilger. Das Verhalten des harnstoffs in der Sammelrohren der Säugetierniere. Pflügers Arch. ges. Physiol. 1958, 267, 238.

7. Maffly, R. H., R. M. Hays, E. Lamdin, and A. Leaf. The effect of neurohypophyseal hormones on the permeability of the toad bladder to urea. J. clin. Invest. 1960, 39, 630.

8. Grantham, J. J., and M. B. Burg. Effect of vasopressin and cyclic AMP on permeability of isolated collecting tubules. Amer. J. Physiol. 1966, 211, 255.

9. Jaenike, J. R. The influence of vasopressin on the permeability of the mammalian collecting duct to urea. J. clin. Invest. 1961, 40, 144.

10. Smith, H. W. The absorption and excretion of water and salts by the elasmobranch fishes. II. Marine elasmobranchs. Amer. J. Physiol. 1931, 98, 296.

11. Truniger, B., and B. Schmidt-Nielsen. Intrarenal distribution of urea and related compounds: effects of nitrogen intake. Amer. J. Physiol. 1964, 207, 971.

12. Clapp, J. R. Renal tubular reabsorption of urea in normal and protein-depleted rats. Amer. J. Physiol. 1966, 210, 1304.

13. Lassiter, W. E., M. Mylle, and C. W. Gottschalk. Micropuncture study of urea transport in rat renal medulla. Amer. J. Physiol. 1966, 210, 965.

14. Manitius, A., G. Pigeon, and F. H. Epstein. Mechanism by which dietary protein enhances renal concentrating ability. Amer. J. Physiol. 1963, 205, 101.

15. Fujimoto, M., F. D. Nash, and R. H. Kessler. Effects of cyanide, $Q_{0}$, and dinitrophenol on renal sodium reabsorption and oxygen consumption. Amer. J. Physiol. 1964, 206, 1327.

16. Herms, W., and R. L. Malvin. Effect of metabolic inhibitors on urine osmolality and electrolyte excretion. Amer. J. Physiol. 1963, 204, 1065.

17. Conway, E. J. Microdiffusion Analysis and Volumetric Error, 4th ed. London, Crosby, Lockwood, 1957, pp. 162-177.

18. Goldberg, M., D. K. McCurdy, E. L. Foltz, and L. W. Bluemle, Jr. Effects of ethacrynic acid (a new saluretic agent) on renal diluting and concentrating mechanisms: evidence for site of action in the loop of Henle. J. clin. Invest. 1964, 43, 201.

19. Snedecor, G. W. Statistical Methods, 5th ed. Ames, Iowa State University Press, 1956.

20. Schmidt-Nielsen, B., and R. O'Dell. Effect of diet on distribution of urea and electrolytes in kidneys of sheep. Amer. J. Physiol. 1959, 197, 856.

21. Aukland; K. Renal tubular permeability to urea. With special reference to accumulation of urea in the renal medulla. Scand. J. clin. Lab. Invest. $1961,13,646$.

22. Kiil, F., and K. Aukland. The role of urea in the renal concentration mechanism. Scand. J. clin. Lab. Invest. 1960, 12, 290. 
23. Levinsky, N. G., D. G. Davidson, and R. W. Berliner. Effects of reduced glomerular filtration on urine concentration in the presence of antidiuretic hormone. J. clin. Invest. 1959, 38, 730.

24. Levinsky, N. G., and R. W. Berliner. The role of urea in the urine concentrating mechanism. J. clin. Invest. 1959, 38, 741.

25. Early, L. E., and R. M. Friedler. Renal tubular effects of ethacrynic acid. J. clin. Invest. 1964, 43, 1495.

26. Lassiter, W. E., C. W. Gottschalk, and M. Mylle. Micropuncture study of net transtubular movement of water and urea in the nondiuretic mammalian kidney. Amer. J. Physiol. 1961, 200, 1139.

27. Owen, E. E., and R. R. Robinson. Urea production and excretion by the chicken kidney. Amer. J. Physiol. 1964, 206, 1321.

28. Brodsky, W. A., N. J. Carlisky, C. F. Gonzalez, and Y. E. Shamoo. Metabolic pathways for urea production by the amphibian kidney. Amer. J. Physiol. $1965,208,546$.

29. Webb, J. L. Enzyme and Metabolic Inhibitors, New York and London, Academic Press, 1966, vol. 3, pp. $61-87$.
30. Schirmer, H. K. A. The effect of intermittent and prolonged renal artery occlusion upon respiration and anaerobic glycolysis of dog kidney. J. Urol. (Baltimore) 1965, 94, 511.

31. Kean, E. L., P. H. Adams, R. W. Winters, and R. E. Davies. Energy metabolism of the renal medulla. Biochim. biophys. Acta (Amst.) 1961, 54, 474.

32. Schmidt-Nielsen, B., and L. Rabinowitz. Methylurea and acetamide: active reabsorption by elasmobranch renal tubules. Science 1964, 146, 1587.

33. Rabinowitz, L., and R. H. Kellogg. Enhancement of renal concentrating ability in the dog by urea and related compounds. Amer. J. Physiol. 1963, 205, 112.

34. Gardner, K. D., Jr., and R. H. Maffly. An in vitro demonstration of increased collecting tubular permeability to urea in the presence of vasopressin. J. clin. Invest. 1964, 43, 1968.

35. Capek, L., G. Rumrich, and K. J. Ullrich. Permeabilität der corticalen Tubulusabschnitte von Ratten für Harnstoff. Pflügers. Arch. ges. Physiol. 1965, 283, 24. 